A similar patient, in whom the ganglion was recently blocked by Mr. Negus with cocaine, could notice no benefit even of temporary nature. We did not think the experiment conclusive, as there was in this case concurrent conjunctivitis.

I wish to thank Messrs. T. Cawthorne, A. D. Griffith, V. E. Negus, S. Nevin, A. Sorsby, and I. A. Tumarkin for kind advice and explanations.

\title{
REFERENCES
}

BogoraD (1928).-(Cited Kaminsky.) Wratschebnoje djelo (Russ.).

KAMINSKY, S D. (1929).-Deutsche Zeitschr.f. Nervenheilk., Vol. CX, pp 151-160.

RUSKIN, S. L. (1928).-Archiv. of Oto-laryngology, Vol. VII, pp. 351-358

SlUDER, G. (1927). - Nasal Neurology, Headaches and Eye Disorders. H. Kimpton, London, pp. 123-130.

TUMARKIN, I. A. (1936).-Lancet, Vol. I, p. 26.

(1936).-Proc. Roy. Soc. Med., Vol. XXIX, pt. 2, pp. 1685-1€91.

\section{ON THE LOCALISATION OF THE MERIDIAN DETERMINED BY PERIMETRIC MEASUREMENT ON THE OUTSIDE OF THE SCLERA}

\author{
BY \\ Prof. I. AbRamowicz \\ UNIVERSITY EYE CLINIC, WILNO, POLAND
}

THE transfer of the meridian determined by the angle which the plane of the arc of the perimeter forms with the horizontal is not simple. Being done at sight gives only approximate results. Then several authors, Lindner, Zykulenko and others, use for this purpose complicated instruments similar to a goniometer, which

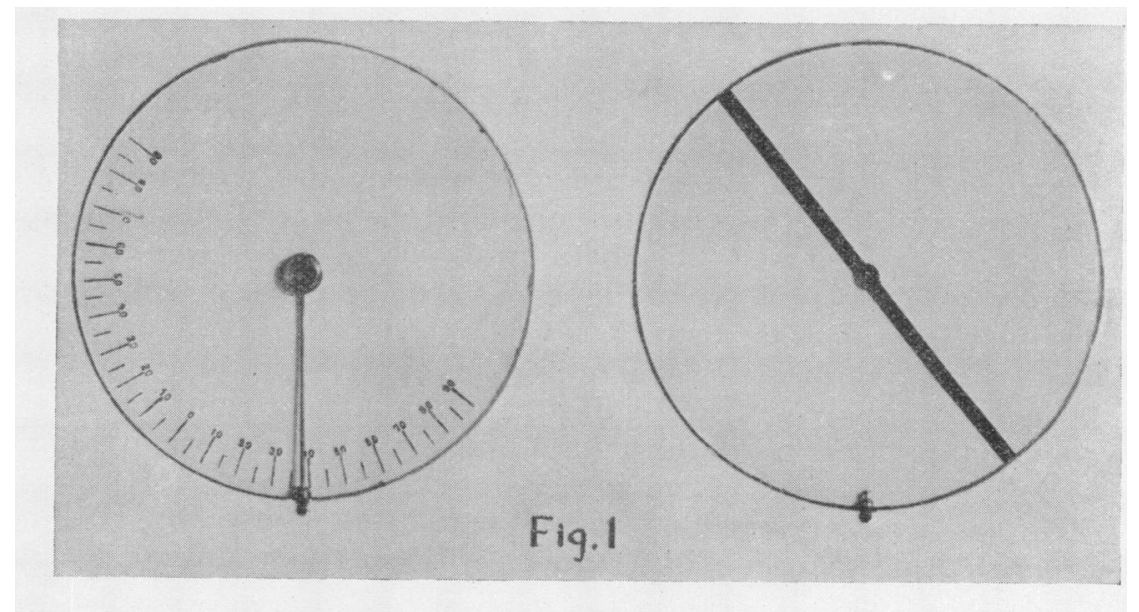


are transferred to the patient's eye. A much more simple method is that of Klein, who uses as his fixation light on the perimeter a filament lamp which rotates with the arc, the image of which is then projected upon the eye, see Duke-Elder's Text-Book of Ophthalmology, Vol. II.

I take the liberty to offer a new simple method, founded on keratoscopic examination, Fig. 1. Instead of concentric rings across the centre of the disc is drawn a black line, which passes through the zero, marked on the back of the disc. Here is placed, similar to the keratoscope of Weve, a metallic rod with weighta plummet-fastened to the movable frame of the magnifyingglass, $6.0 \mathrm{D}$., placed in the hole of the disc. The rod determines a perpendicular, $0^{\circ}$, or a declination.

The proceeding is simple: we set the metallic rod suitable to the site of the arc of the perimeter, in the Fig. $52^{\circ}$ from the horizontal, and holding the disc parallel to the iris or suspending it on the free end of the rod at a distance of about $12 \mathrm{~cm}$., the diameter of the disc is $33 \mathrm{~cm}$., we look at the corneal image. The image of the centre of the disc shall be brought to the centre of the cornea. The image of the black line indicates the meridian of longitude, determined by perimetric measurement, in which the retinal landmark is situated. The two points on opposite sides of the limbus are marked with some indicator.

\section{ANNOTATION}

\section{Recent changes in some Continental Ophthalmological Journals}

The Zeitschrift für Augenheilkunde now appears as "Ophthalmologica." It is published as an international journal of ophthalmology at Basel and contains articles in English, French and German. The list of editors is world-wide and we note that for Britain these are A. J. Ballantyne, Sir S. Duke-Elder, Mr. C. B. Goulden and Miss Ida Mann. We understand that the Archiv. für Ophthalmologie and the Archiv. für Augenheilkunde have been recently amalgamated. We do not know what facts underlie these changes. The causes of amalgamation of the two Archiv. may possibly be financial. Like Mr. Squeers, when Bolder's father was two pound ten short, they may have had disappointments to contend against. The financing of an ophthalmological journal is never an easy matter in any country. Union usually means strength and under conditions as they are to-day in Central Europe there may not be sufficient material to enable two large journals such as the 